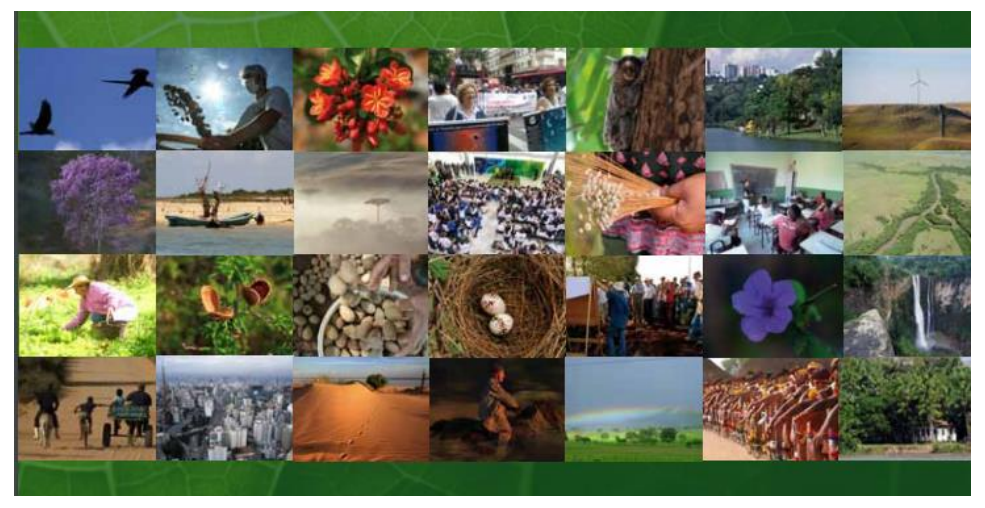

\title{
Um olhar político para a educação ambiental do Programa Nacional De Educação Ambiental (ProNEA)
}

\author{
A discourse analysis of the brazilian national \\ program of environmental education (ProNEA)
}
Andréa Quirino de Luca ${ }^{1}$ Suzy Maria Lagazzi ${ }^{2}$ Marcos Sorrentino ${ }^{3}$

Resumo: Este trabalho, que se localiza no terreno da Educação Ambiental, tem como perspectiva teórico-metodológica a Análise de Discurso de linha materialista, e procura compreender a historicidade do documento da política pública de educação ambiental do Brasil, nomeado Programa Nacional de Educação Ambiental - ProNEA -, assim como dar visibilidade aos pré-construídos e condições de produção que sustentam seu discurso. Apresentamos alguns pressupostos do referencial teórico-metodológico, o contexto da política pública, e a análise realizada. Terminamos o artigo com algumas considerações de ordem teórico-analítica, abrindo as possibilidades de reflexão com novas perguntas. Pretendemos contribuir com um melhor entendimento sobre o discurso da educação ambiental do ProNEA, dando visibilidade ao modo pelo qual o sentido de política pública se produz.

Palavras-chave: Educação ambiental; Política pública de educação ambiental; Análise de discurso.

Abstract: In this work, which is in the field of Environmental Education, we conducted a materialistic discourse analysis to understand the historical references of document of public policy on environmental education in Brazil, the National Program of Environmental Education (ProNEA). We seek to give visibility to the pre-built and production conditions that support this speech. We present the assumptions of the materialistic discourse analysis, the context of public policy for environmental education in Brazil, and analysis performed. We finished the work with some theoretical-analytical considerations, opening the possibilities of reflection with new questions. We intend to contribute to a better understanding of the discourse of public policy on environmental education in Brazil, giving visibility to the way in which the meaning of public policy is produced.

\footnotetext{
1 Laboratório Oca de Educação e Política Ambiental - Depto de Ciências Florestais/ESALQ/USP, Bióloga, especialista em Educação Ambiental, Mestre em Recursos Florestais, doutora em Ciências pelo PROCAM/USP; andreaqluca@gmail.com. Rua João Batista Grigol, 80B, Campinas, SP, CEP: 13085-335 2 Professora do Departamento de Estudos da Linguagem da Unicamp, Analista de Discurso; slagazzi@gmail.com. Cidade Universitária Zeferino Vaz, Barão Geraldo, Campinas, SP, CEP: 13083970, Caixa Postal 6045

3 Professor do Depto de Ciências Florestais da ESALQ/USP e Coordenador do Laboratório Oca de Educação e Política Ambiental dessa Instituição; sorrentino.ea@gmail.com. Avenida Pádua Dias, 11, Piracicaba, SP, CEP: 13418-900, Caixa Postal 9.
} 
Keywords: Environmental education; Public policy on environmental education; Discourse analysis.

\section{Condições de produção do ProNEA ${ }^{4}$}

Os anos 90 demarcam importantes momentos para a história da institucionalização da Educação Ambiental (EA) no Brasil. Em 1992, é criado o Ministério do Meio Ambiente (MMA) e, nesse mesmo ano, os Núcleos de EA do IBAMA foram instituídos em todas as superintendências estaduais, a fim de operacionalizar ações educativas na gestão estadual (BRASIL, 2005).

Em 1994, o governo federal criou o Programa Nacional de Educação Ambiental (PRONEA), porém a criação da Política Nacional de Educação Ambiental (PNEA) só ocorre em 1999.

A PNEA foi regulamentada em 2002 pelo decreto 4.281/02, tendo sido definido, nesse momento, o Órgão Gestor de EA, composto pelos Ministros do Meio Ambiente e da Educação. Em junho de 2003, os dois Ministros nomeiam os seus setores responsáveis pela área de EA para os representarem na implantação da Política. Esse decreto também prevê as competências desse Órgão para o cumprimento da PNEA, entre outras providências (Brasil, 2002). A partir desse documento é que a EA passa a ser constituída como um componente essencial e permanente da educação nacional (SORRENTINO et al., 2007).

O Órgão Gestor da PNEA publica, a partir de uma consulta pública, três versões do ProNEA (2003, 2004 e 2005, respectivamente), que se diferencia do PRONEA, versão anterior à entrada do presidente Luiz Inácio Lula da Silva.

O contexto político na criação do ProNEA configurava-se pela entrada do então presidente Luiz Inácio Lula da Silva, do Partido dos Trabalhadores, ex-líder sindical, que nomeou Maria Osmarina Marina Silva ao cargo de Ministra do Meio Ambiente. Marina Silva, que nasceu e viveu muitos anos no interior do Acre e que atuou politicamente com o líder seringueiro Chico Mendes, foi ministra até maio de 2008. Portanto, essa configuração política que traz uma marca de "povo no poder" e de “movimento social político no Estado" estava em efervescência em 2003 e 2004. Marina Silva nomeou como diretor do Programa Nacional de EA - que depois se transformaria em Diretoria de EA e, finalmente, em Departamento de Educação Ambiental (DEA) do MMA - o Prof. Dr. Marcos Sorrentino, do departamento de

${ }^{4}$ Este artigo é parte de tese realizada em Ciência Ambiental pelo PROCAM/USP, e teve auxílio FAPESP (2010/17695-3). Esta é uma versão modificada de artigo apresentado no GT de EA do VI Encontro Nacional da ANPPAS, Belém, 2012. 
Ciências Florestais da ESALQ/USP.

O Órgão Gestor da Política Nacional de EA (Brasil, 1999; 2006a), então à frente da política pública de EA e, assim, do ProNEA, era dirigido pelos ministros de meio ambiente (Marina Silva) e de educação (Cristovão Buarque, que depois foi sucedido por Tarso Genro e em seguida por Fernando Haddad), tendo como representantes, pelo DEA/MMA, Marcos Sorrentino e equipe e pela Coordenação Geral de Educação Ambiental do Ministério de Educação (CGEA/MEC), inicialmente a professora da UnB, Laura Goulart Duarte, e em seguida Rachel Trajber e equipe (nomeada pelo ministro Tarso Genro e mantida por Fernando Haddad).

O documento da política pública de educação ambiental do Brasil, o ProNEA, em sua terceira edição (Brasil, 2005) - também disponível para consulta no portal do MMA, em: http://www.mma.gov.br/estruturas/educamb/arquivos/pronea3.pdf (consultado em 10/05/14) -, constitui o campo discursivo deste artigo. Para apoiar tal análise, utilizamos também um artigo construído por membros do Órgão Gestor da Política Nacional de Educação Ambiental, que trata do ProNEA (SORRENTINO et al., $2005)^{5}$.

\section{Entrando no texto do ProNEA}

A apresentação que consta do texto do ProNEA marca a sintonia com outro documento, o Tratado de Educação Ambiental para Sociedades Sustentáveis e Responsabilidade Global (Tratado de EA), contido integralmente em seu Anexo 1. O Tratado de EA é um documento produzido a muitas mãos durante a Conferência da ONU Rio-92, pelo Fórum Internacional de ONGs e Movimentos Sociais, com a participação de mais de 1300 ONGs. O texto da apresentação também nos 'conta' que o documento trata das diretrizes, princípios e missão, que orientam as ações do ProNEA.

Por sua vez, o ProNEA foi o balizador para a criação do ProFEA - Programa de Formação de Educadoras(es) Ambientais: por um Brasil educado e educando ambientalmente para a sustentabilidade (Brasil, 1999; 2005; 2006b).

Ainda na apresentação do ProNEA, temos uma explicação sobre a consulta pública realizada em 2004, que teve a participação de mais de 800 educadores

\footnotetext{
${ }^{5}$ Em 2014 foi publicada a quarta edição (BRASIL, 2014) que inclui instrumentos legais e normativos da EA, cuja versao não foi objeto de análise desse trabalho por ter sido realizada anteriormente a essa publicação.
} 
ambientais de 22 unidades federativas do país, o que, por um lado, permitiu uma construção coletiva de sua terceira versão e, concomitantemente, também foi vista como um exercício de apropriação do documento. O método da construção participativa foi realizar oficinas em parcerias com comissões e redes de EA, e a ideia de contribuir com a mobilização (articulação política) desses educadores foi muito valorizada no texto, assim como a ideia de uma 'cultura' da participação.

No mesmo trecho do documento é ressaltado que, apesar de o ProNEA ser um programa de âmbito nacional, sua implementação, aplicação, execução, monitoramento e avaliação não devem ser feitos apenas pelo governo federal, mas também por outras esferas de governo e segmentos da sociedade civil. Também aponta para a direção de 'construção permanente' do documento, no sentido de que sempre poderá ser aprimorado como aprendizado retroalimentado pelas práticas dos parceiros envolvidos. A proposta deste documento é estar sempre sujeito à constante revisão pública.

O ProNEA constantemente reitera os termos 'participação', 'democracia', 'construir coletivamente', 'co-responsabilidade', 'inacabamento do conhecimento e do documento'. A sua declarada sintonia com os princípios vindos do Tratado de EA já deixa claro ser um documento de oposição ao já-estabelecido. É um documento que trabalha a/na resistência. Mas oposição e resistência a que/quem? É o que procuramos buscar na materialidade do texto.

\section{A nálise de discurso materialista - teoria e metodologia indissociáveis}

O objetivo de um analista de discurso é compreender como um texto funciona, como um texto produz sentidos, amparado por um dispositivo teórico-metodológico (Orlandi, 2008). Um dos pontos de fundamentação do dispositivo teórico-metodológico discursivo de perspectiva materialista é o descentramento do sujeito, questão defendida pelo materialismo histórico, sustentando a noção de que o sujeito não é fonte nem origem de sentido, mas sujeito à língua e à história, indivíduo interpelado a ser sujeito (ORLANDI, 2007).

A língua, por sua vez, não é transparente, simples meio de transmissão de sentidos pré-estabelecidos, mas suporte material sobre o qual se realiza a produção dos sentidos. Embora nos seja apresentada como transparente, a língua é opaca e demanda um investimento de leitura para que o modo da formulação, remetido às condições de produção do texto em questão, possa ser compreendido nas possibilidades de interpretação que comporta. 
Ao lado do materialismo histórico, o materialismo dialético nos apresenta dois princípios básicos: (i) a primazia do real sobre seu conhecimento- a primazia do ser sobre o pensamento, e (ii) a distinção entre o real e o conhecimento- a distinção entre o ser e o pensamento. Jamais poderemos 'dar conta' de compreender o total do mundo, sempre teremos a perspectiva simbólica sobre o real (ALTHUSSER, 1986).

Assim sendo, o mundo não se resume ao que pensamos/significamos sobre ele/dele. Buscamos conteúdos o tempo todo, temos urgência em significar, e temos a tendência a nos estabilizar, ou seja, temos dificuldades com as mudanças. Porém, sempre há espaço para deslizamentos, para um outro possível. A análise de discurso (AD) busca ter um olhar para desnaturalizar e dar visibilidade a estas questões, já que não somos fonte de sentidos, mas agentes-suporte interpelados em memórias discursivas, o dito já-lá, percursos de dizer já-ditos (ORLANDI, 2007).

E o percurso que realizamos no acontecimento de nosso discurso é o intradiscurso, trajeto político que percorremos e que aponta uma direção, ao deixar de apontar tantas outras possíveis e outras não possíveis. Digo " $\mathrm{x}$ " em determinadas condições de produção, quando poderia dizer “y”, “z” ou “w”, e não poderia dizer "m", “n” ou "p". O dizer é regulado pelas condições de produção, pela posição do sujeito, pela memória do dizer. Nem apenas um sentido, nem qualquer sentido. Recortes dentro do possível.

O 'sempre-já-aí', diz Pêcheux (2009, p.151), corresponde ao pré-construído da interpelação ideológica, que "fornece/impõe a realidade e seu sentido sob a forma da universalidade (o 'mundo das coisas'), (...)". O intradiscurso refere-se ao "fio do discurso' de um sujeito: "o que eu digo agora, com relação ao que eu disse antes e ao que eu direi depois" (Ibid., p.153).

Desta forma, a noção de memória discursiva, que constitui o 'dizível', permite formulações de acordo com as posições discursivas, em seus contextos e condições de produção, sendo o significante sempre investido por diferentes sentidos dependendo das condições e posições discursivas. O sentido é sempre sentido para e não sentido em si (ORLANDI, 2007; PÊCHEUX, 2009).

As condições de produção dos sentidos são determinações que regulam o trabalho de interpretação de sujeitos que estão em certas condições políticas, econômicas, em meio a percursos históricos dos sentidos, num sistema de evidências e de significações percebidas-aceitas-experimentadas por todos (PÊCHEUX, Op. Cit.).

A ideologia é entendida como uma representação constitutiva da relação 
imaginária dos indivíduos com suas condições reais de existência, sendo um processo sem sujeito nem fim (ALTHUSSER, 1978).

Porém, não há nenhuma relação que seja apenas de fora para dentro. Nos termos do assujeitamento, sempre a questão da identificação faz com que o sujeito se reconheça em sentidos para poder movimentar esse processo - só há ideologia pelo sujeito e para o sujeito, só há prática através de e sob uma ideologia (Althusser, 1986).

Diferente de concepções encontradas em outras áreas de saber, para a $\mathrm{AD}$ a ideologia não é alienação ou falsa consciência. Ou seja, o sujeito nunca sai da ideologia para atingir a conscientização, não há um 'total' ou uma quantificação quando se trata de conscientização. Ideologia, assim, é a mediação entre os homens e suas condições materiais de existência, com relações de poder que regem a sociedade, elaboradas simbolicamente, num processo de produção de sentidos tidos como naturalizados e que, assim, passam a constituir o 'senso comum' (ORLANDI, 2008; RODRÍGUEZALCALÁ, 2005).

De acordo com Althusser (1974, p.95):

Como todas as evidências, incluindo as que fazem com que uma palavra designe uma coisa ou possua uma significação (portanto incluindo as evidências da transparência da linguagem), esta evidência de que eu e você somos sujeitos - e que esse fato não constitui problema - é um efeito ideológico, o efeito ideológico elementar. Aliás, é próprio da ideologia impor (sem o parecer, pois que se trata de evidências) as evidências como evidências, que não podemos deixar de reconhecer, e perante as quais temos a inevitável reação de exclamarmos (em voz alta ou no silêncio da consciência): é evidente! É isso! Não há dúvida!

A perspectiva materialista pensa a língua como estrutura falha, no sentido de haver espaço para o movimento da estrutura, portanto os sentidos não são estáticos (LAGAZZI, 2010a). O discurso é a língua na história, significante na história. As ideias são atos materiais inseridos em práticas materiais, reguladas por rituais materiais. Os sujeitos e os sentidos se repetem e se deslocam (ORLANDI, 1999).

Os procedimentos da $\mathrm{AD}$ começam, assim, com o contato do analista com o texto, para desfazer o entendimento de que aquilo que foi dito daquela maneira só poderia ter sido dito assim, ou seja, para desnaturalizar a relação palavra-coisa. O analista utiliza a paráfrase e a metáfora como conceitos que permitem o exercício com a materialidade significante (LAGAZZI, 2010a), considera a posição de onde os sentidos se produzem, tentando compreender as formações discursivas que configuram o 
funcionamento discursivo em questão (ORLANDI, 1999).

\section{Buscando 'marcas' no texto do ProNEA}

Saiu o semeador a semear. Semeou o dia todo e a noite o apanhou ainda com as mãos cheias de sementes. Ele semeava tranquilo, sem pensar na colheita porque muito tinha colhido do que outros semearam." (Poema de Cora Coralina apresentado na abertura do ProNEA - BRASIL, 2005, p.1).

Esta é a abertura do documento: uma poesia de Cora Coralina, poetisa brasileira, goiana (Ana Lins dos Guimarães Peixoto Bretas, 1889 - 1985). Nela o semeador tem tranquilidade pois está ligado a outros semeadores, já colheu colheitas de outrem. Aponta para a direção de coletividade, traz para o semeador a tranquilidade do gesto solidário sobre o egoísmo, o 'nós' sobre o 'eu', apesar de se tratar do 'eu', do semeador no singular.

A valorização da coletividade e de processos coletivos, assim como a questão da participação, aparecem como fortes noções no ProNEA (Brasil, 2005), como vemos a seguir (p.15-16, 'Apresentação', texto integral, grifos nossos):

Este documento, sintonizado com o Tratado de Educação Ambiental $^{6}$ para Sociedades Sustentáveis e Responsabilidade Global, apresenta as diretrizes, os princípios e a missão que orientam as ações do Programa Nacional de Educação Ambiental -ProNEA, a delimitação de seus objetivos, suas linhas de ação e sua estrutura organizacional.

A presente versão é resultado de processo de Consulta Pública, realizado em setembro e outubro de 2004, que envolveu mais de 800 educadores ambientais de 22 unidades federativas do país, configurando a construção participativa do Programa Nacional de Educação Ambiental e que se constitui ao mesmo tempo, num processo de apropriação do ProNEA pela sociedade. A Consulta Pública do ProNEA foi realizada em parceria com as Comissões Interinstitucionais Estaduais de Educação Ambiental (CIEAs) e as Redes de Educação Ambiental, em Oficinas intituladas "Construindo juntos o futuro da educação ambiental brasileira", e se tornou uma oportunidade de mobilização social entre os educadores ambientais possibilitando o debate acerca das realidades locais para subsidiar a elaboração ou implementação das Políticas e Programas estaduais de

\footnotetext{
${ }^{6} \mathrm{~A}$ partir das análises realizadas e presentes na tese em questão, é possível afirmar que o Tratado de EA valoriza a participação em processos coletivos. A construção deste documento, como dito, teve a participação de 1300 ONGs com atuação em 108 países.
} 
educação ambiental.

Importante ressaltar que o ProNEA é um programa de âmbito nacional, o que não significa que sua implementação seja de competência exclusiva do poder público federal, ao contrário, todos os segmentos sociais e esferas de governo são co-responsáveis pela sua aplicação, execução, monitoramento e avaliação.

Reconhecendo seu estado de permanente construção, em consonância com o delineamento das bases teóricas e metodológicas da educação ambiental no Brasil, a Diretoria de Educação Ambiental do MMA, a Coordenação Geral de Educação Ambiental do MEC e o Órgão Gestor entendem ser necessário prever uma estratégia de planejamento incremental e articulada, que permita revisitar com frequência os seus objetivos e estratégias, para seu constante aprimoramento, por meio dos aprendizados sistematizados e dos redirecionamentos democraticamente pactuados entre todos os parceiros envolvidos. Mas, sem renunciar à formulação e à enunciação de seus objetivos e sem abandonar as diretrizes e os princípios que balizam as ações em educação ambiental no governo federal.

Nesse sentido, a expectativa é estabelecer uma periodicidade para revisões futuras do ProNEA - objetivando seu aperfeiçoamento constante - em espaços que possibilitem o debate democrático e a construção participativa, a exemplo do Fórum Brasileiro de Educação Ambiental.

Quais premissas podemos entender estão sob as bases do ProNEA, determinando os sentidos da educação ambiental em seu programas e políticas públicas? Ressaltamos, do recorte acima, os trechos "configurando a construção participativa", "parceria", "não significa que sua implementação (do ProNEA) seja de competência exclusiva do poder público federal, ao contrário, todos os segmentos sociais e esferas de governo são co-responsáveis pela sua aplicação, execução, monitoramento e avaliação", "democraticamente pactuados entre todos os parceiros envolvidos", "debate democrático e a construção participativa", que marcam como eixo temático central das ações demandadas para a educação ambiental, a participação e a parceria.

Nestes termos de participação e parceria, a direção apontada é a de que o Estado é um importante parceiro da sociedade, como visto acima: "Importante ressaltar que o ProNEA é um programa de âmbito nacional, o que não significa que sua implementação seja de competência exclusiva do poder público federal, ao contrário, todos os segmentos sociais e esferas de governo são co-responsáveis pela sua aplicação, execução, monitoramento e avaliação".

Parceiro articulador de processos participativos, que 'serve' a sociedade, que promove encontros para debates, que não devem se fechar, mas se refazer a partir da experiência das pessoas que atuam em termos socioambientais: "constante 
aprimoramento, por meio dos aprendizados sistematizados e dos redirecionamentos democraticamente pactuados entre todos os parceiros envolvidos."

Partilha de poder com a sociedade, 'permitindo' que políticas sejam avaliadas por variados setores, sendo importante ressaltar que a temática desse discurso não trabalha na direção de dissolução do Estado: "estabelecer uma periodicidade para revisões futuras do ProNEA - objetivando seu aperfeiçoamento constante - em espaços que possibilitem o debate democrático e a construção participativa (...).”

A questão da cidadania como participação está também presente. Essa é a premissa da cidadania nesse entendimento. E essa questão está intimamente ligada com a questão da coletividade: trabalha no sentido de 'deixar claro' que podemos semear sozinhos, mas a colheita é coletiva, ou seja, a coletividade é aqui constitutiva. E democracia e participação estão 'enlaçadas', assim como a noção de coresponsabilidade. Nas diretrizes que o documento aponta, encontramos essas ideias de democracia e participação vinculadas, de descentralização do poder do Estado, da questão da coletividade que aqui também aparece significada por transversalidade e interdisciplinaridade (BRASIL, 2005, p.33):

- Transversalidade e Interdisciplinaridade.

- Descentralização Espacial e Institucional.

- Sustentabilidade Socioambiental.

- Democracia e Participação Social.

Ainda sobre o vínculo democracia e participação, também presente no texto da seção Diretrizes (Ibid., p.34, grifos nossos):

A descentralização espacial e institucional também é diretriz do ProNEA, por meio da qual privilegia o envolvimento democrático dos atores e segmentos institucionais na construção e implementação das políticas e programas de educação ambiental nos diferentes níveis e instâncias de representatividade social no país.

Considerando-se a educação ambiental como um dos instrumentos fundamentais da gestão ambiental, o ProNEA desempenha um importante papel na orientação de agentes públicos e privados para a reflexão, a construção e a implementação de políticas públicas que possibilitem solucionar questões estruturais, almejando a sustentabilidade socioambiental. Assim, propicia-se a oportunidade de ressaltar o bom exemplo das práticas e experiências exitosas, como a integração entre professores e técnicos ambientais em programas de formação.

A democracia e a participação social permeiam as estratégias e açõessob a perspectiva da universalização dos direitos e da inclusão social por intermédio da geração e disponibilização de informações que garantam a participação social na discussão, formulação, implementação, fiscalização e avaliação das políticas ambientais 
voltadas à construção de valores culturais comprometidos com a qualidade ambiental e a justiça social; e de apoio à sociedade na busca de um modelo socioeconômico sustentável.

A participação e o controle social destinam-se ao empoderamento dos grupos sociais para intervirem, de modo qualificado, nos processos decisórios sobre o acesso aos recursos ambientais e seu uso. Neste sentido, é necessário que a educação ambiental busque superar assimetrias nos planos cognitivos e organizativos, já que a desigualdade e a injustiça social ainda são características da sociedade. Assim, a prática da educação ambiental deve ir além da disponibilização de informações.

Aqui o poder aparece como processo de qualificação que permite a participação para decisões substantivas (acesso aos recursos ambientais). Fica entendido que os sentidos trabalham numa direção de 'desenvolver' (incrementar) a questão de democracia participativa, orientando as ações e fomentando a intervenção de seus atores. Isso nos mostra que a educação ambiental vai sendo ratificada na relação direta com os sujeitos dessas práticas em suas potencialidades.

Assim como no documento Tratado de $\mathrm{EA}^{7}$, no ProNEA também não se usa o termo 'desenvolvimento sustentável' e no 'lugar' aparece o termo 'sociedades sustentáveis', termo de oposição, de discordância em relação ao primeiro, que vem sendo amplamente utilizado, inclusive por instituições governamentais, empresariais e não governamentais em geral. Pode ser entendido como um documento de resistência a esse gesto tão repetido na atualidade, um documento que se ancora na denúncia do Tratado de EA.

A palavra 'sustentabilidade' vem acompanhada de socioambiental, que é assim explicada numa nota de rodapé (Ibid., p.18):

Embora reconheçamos o caráter multidimensional da questão ambiental, entendemos ser necessário enfatizar a articulação entre a dimensão social e a dimensão ambiental, motivo pelo qual apresentamos neste documento a formulação "socioambiental" em vez de simplesmente ambiental.

Dessa forma, busca dar sentido de historicidade com a chamada 'causa ambiental'. Esse discurso não se filia, então, a um tipo que, segundo Orlandi (2004, p.65), paira sobre a cidade e que é típico de alguns ecologistas onde "a cidade seria uma monstruosa agressão do homem à natureza" e que "o mundo seria salvo por uma romântica volta ao campo".

E ainda sobre isso, em artigo publicado por membros do Órgão Gestor de EA

${ }^{7}$ Consideração possível a partir de análise discursiva do Tratado de EA durante doutoramento, presente na tese em questão. 
sobre a política pública de EA e sobre o ProNEA (SORRENTINO et al., 2005, p.289):

(...) o conceito de desenvolvimento sustentável indica claramente o tratamento dado à natureza como um recurso ou matéria-prima destinado aos objetivos de mercado cujo acesso é priorizado a parcelas da sociedade que detém o controle do capital. Nesse sentido, passamos a vislumbrar como meta uma educação ambiental para a sustentabilidade socioambiental.

Encontramos no ProNEA (BRASIL, 2005, p.17): “É preciso também considerar que uma significativa parcela dos brasileiros tem uma percepção 'naturalizada' do meio ambiente, excluindo homens, mulheres, cidades e favelas desse conceito".

Esta formulação nos permite entender que o sentido de meio ambiente trazido pelo documento articula a dimensão espaço, sujeito e história. Neste recorte, podemos parafrasear "percepção naturalizada" por "percepção estabilizada", "percepção legitimada”, que não 'enxerga' relações em movimento. Nesse ponto quero trazer uma contribuição da $\mathrm{AD}$ : a relação sujeito-espaço-linguagem é constitutiva, é um tripé de sustentação para significarmos.

Ainda no artigo sobre o ProNEA (SORRENTINO et al., 2005, p.287, grifos nossos), temos a seguinte citação: “A educação ambiental, em específico, ao educar para a cidadania, pode construir a possibilidade da ação política, no sentido de contribuir para formar uma coletividade que é responsável pelo mundo que habita."

Nesse recorte a 'educação ambiental' fica sobredeterminada por 'educar para a cidadania', e tem o objetivo da ação política, na qual a ideia de co-responsabilidade e coletividade estão unidas à noção de um outro Estado: "nasce a ideia de uma nova ordem e de novos valores que implicam uma nova estrutura, um novo Estado“ (Ibid., idem).

Fica reiterada, ainda, para a educação ambiental, a direção de oposição ao neoliberalismo e reforçado o sentido de participação como assunção das responsabilidades individuais e coletivas (grifos nossos):

Nas décadas de 1970 e 1980 vivemos um período no qual a doutrina neoliberal impôs o conceito de Estado mínimo, de regulação mínima, ao mesmo tempo em que a crescente complexidade da sociedade exigia mais regulação e maior inserção do Estado em novas questões. A sociedade sente a necessidade de mais Estado, enquanto a opinião pública posiciona-se mais como anti-Estado. (...) $\underline{\mathrm{O} \text { resgate do caráter }}$ público do Estado requer sua ampliação no âmbito da educação e do ambiente. Um Estado cresce quando suas funções históricas passam a demandar mais ação (crescimento horizontal do Estado) ou quando ele é impelido a assumir novas funções (crescimento vertical do Estado). Este último é qualitativo, enquanto aquele é quantitativo, de modo que 
a função reguladora do Estado no campo ambiental é um incremento qualitativo do Estado, ou seja, uma nova função. Neste artigo tecemos algumas considerações sobre as políticas públicas voltadas à questão socioambiental, especificamente a educação ambiental, a qual tem por finalidade abrir espaços que possam contribuir para a melhoria da qualidade de vida dos seres humanos e de todas as espécies e sistemas naturais com os quais compartilhamos o planeta ao longo dos tempos. Isso se dá ao assumirmos nossas responsabilidades individuais e coletivas, interligadas pelas circunstâncias sociais e ambientais. Responsabilidade exige, entre outras coisas, autonomia para a participação no debate de políticas públicas (...) (Ibid., p.287-288).

$\mathrm{O}$ recorte trazido acima sustenta ideias de um Estado presente, com uma nova função, relacionada à questão ambiental, mais especificamente à EA, pela participação e co-responsabilidade socioambiental: "mais regulação e maior inserção do Estado em novas questões", "a sociedade sente a necessidade de mais Estado", "o resgate do caráter público do Estado requer sua ampliação no âmbito da educação e do ambiente", "um Estado cresce quando suas funções históricas passam a demandar mais ação", "assumirmos nossas responsabilidades individuais e coletivas", "autonomia para a participação no debate de políticas públicas”.

Ainda tentando dar visibilidade às conexões que o ProNEA enreda, a educação ambiental vem mais uma vez unida à ideia de ação política quando vem com uma dupla função: "propiciar os processos de mudanças culturais (...) e de mudanças sociais (...)" (Brasil, 2005, p.18). Pretende promover articulação de ações e setores e almeja ver a EA no planejamento estratégico do governo federal do país (Ibid.).

Vejamos neste recorte da seção Justificativas do ProNEA, as marcas da regularidade da direção desse documento que busca sustentar as ações de EA para a transformação, pela participação coletiva, mantendo o alinhamento à área de EA delimitada pelo Tratado de EA, em oposição à EA desenvolvimentista (grifos nossos):

E nesse contexto, em que os sistemas sociais atuam na promoção da mudança ambiental, a educação assume posição de destaque para construir os fundamentos da sociedade sustentável, apresentando uma dupla função a essa transição societária: propiciar os processos de mudanças culturais em direção à instauração de uma ética ecológica e de mudanças sociais em direção ao empoderamento dos indivíduos, grupos e sociedades que se encontram em condições de vulnerabilidade em face dos desafios da contemporaneidade. (...) Portanto, é no sentido de promover a articulação das ações educativas voltadas às atividades de proteção, recuperação e melhoria socioambiental, e de potencializar a função da educação para as mudanças culturais e sociais, que se insere a educação ambiental no planejamento estratégico do governo federal do país. 
A partir dos recortes trazidos, temos como efeitos de sentido que o Estado é um importante articulador da ação política entendida como democracia que, necessariamente para assim se configurar, está ligada à participação em processos plurais: "é no sentido de promover a articulação das ações educativas voltadas às atividades de proteção, recuperação e melhoria socioambiental, e de potencializar a função da educação para as mudanças culturais e sociais, que se insere a educação ambiental no planejamento estratégico do governo federal do país."

A EA tem um caráter socioambiental vinculado a essa ação política. A cidadania é resultado desse enredo da ação política, que configura a democracia almejada, objetivo desse texto/documento de Estado: “a educação assume posição de destaque para construir os fundamentos da sociedade sustentável, apresentando uma dupla função a essa transição societária (...)".

Dessa forma, as direções apontadas pelo ProNEA se relacionam com a análise de discursos de EA realizadas por Silva (1996), que tratam da questão ambiental como a possibilidade de o ambientalismo ocupar o lugar do político, sem que o sujeito possa se ver e se mostrar como sujeito político. Pelos recortes trazidos na análise desse capítulo, o ProNEA é um documento que se contrapõe à sociedade de consumo e que se coloca numa posição crítica em relação a processos de exploração socioambiental, ancorado na pauta do coletivo, o que nos permite trazer a definição de coletivo trazida por Silva (idem): "é a inscrição histórica do sujeito através dos vínculos que o ligam concretamente ao ambiente que o cerca" (Ibid., p.58).

\section{Adensando as questões}

Perguntamos: a noção de política pública, vinculada à ação política para planejar e provocar transformações no tecido social e seus funcionamentos, mostra um deslocamento de sentido desses termos (política pública, ação política, cidadania)? E ainda, a ideia de 'nova' função do Estado proferida de 'dentro' desse Estado chega a atualizar o discurso de aparelho (ao invés de uma posição estabilizada de autoritarismo), em direção a se constituir como um parceiro articulador? Vejamos.

O sexto princípio do documento (Ibid., p.37) é "compromisso com a cidadania ambiental”, que se entrelaça com essa ação política coletiva, que a impõe. Para Orlandi (2010b) todos já nascemos cidadãos pois nascemos em uma república, apesar de haver um discurso social que nega ou atribui cidadania, presente no imaginário do mundo 
capitalista. Para Lagazzi (2010b, p.81) ser cidadão "é ter consciência de que se é sujeito de direitos, e também de deveres".

Procurando fazer uma reflexão sobre cidadania, me vinculo aqui à noção de social (socialis) trazida por Orlandi (1999b, p.11), que se define como "relativo àquele que é portador da sociabilidade", afirmando que a violência individualiza, enfraquece as relações. E, nessa direção, filio-me a esta autora quando afirma que "faltam experiências de socialização e falta até mesmo o aprendizado da convivência com os outros. A experiência social está rarefeita" (Ibid., p.78). E também que "o isolamento tem criado (...) uma grande incapacidade de estabelecer e manter laços de sociabilidade (amizade, solidariedade)", e assim os sujeitos abandonam os laços sociais que é o que poderia lhes dar maior segurança (Ibid., idem).

Diz a autora (Ibid., p.79):

Há uma geografia da violência, uma lógica da violência, uma economia da violência. Para fazer face a isso, temos de aprender novas formas de sociabilidade, novos modos de nos pensar coletivamente, não reagindo pelo medo, reivindicando condições de sociabilidade praticáveis, mobilizando instituições, mídia, configurando programas que atendam essas novas necessidades (...) temos de conquistar o espaço-tempo de nossa contemporaneidade social e política que é habitar a cidade sem restrições: nosso lugar público, social, político.

Ancoro-me na direção do conceito de cidadania não como uma essência, como dito por Orlandi (2004, p.65), mas como um cruzamento da história e como significamos a partir dos sentidos da cidade que é governada pelo Estado. Se para o Estado já somos sempre cidadãos, desde que nascemos em uma República, "resta saber como esta cidadania é significada nos modos como os sujeitos são individualizados pelo Estado, através de suas instituições”. Para que não haja esvaziamento do sentido do que é cidadania, é necessário dar espaço à socialização e seus conflitos, reafirmar nossa capacidade de sociabilidade (Ibid.).

A cidadania apresentada pelo ProNEA passa pelo encontro dos sujeitos participando e decidindo ao lado do Estado. O político se constitui necessariamente, aqui, como espaço das relações com suas tensões constitutivas e divisões e, nestes termos, a socialização pode tornar visível as relações de dominação política. O contrário seria uma situação de impossibilidade de relações, com um individualismo provocado, se renovando e se desenvolvendo, o que também seria uma posição política (posiçãosujeito) que nega o espaço das relações (LAGAZZI, 1987). 
A sociabilidade como cidadania permite-nos pensar não pela lógica da violência e da repressão, conceitos homogêneos em sua circulação pela mídia, mas na direção de uma vida pública rica, com medidas que possam ser formadoras, na lógica da sociabilidade e do alargamento do espaço público (ORLANDI, 2010a).

A fim de enriquecer a discussão sobre cidadania, trago aqui Naves (2008), e as reflexões postas por Lagazzi (2010b), realizadas a partir do estudo de Naves (Op. Cit.) sobre Evgeni Pachukanis, autor russo que escreveu 'A teoria geral do direito e o marxismo', publicado em 1924. Pachukanis discute o direito na relação com o capitalismo e o socialismo, e traz elementos sobre o funcionamento do jurídico no cotidiano e sobre cidadania, o que nos permite compreender melhor a relação do Estado com a sociedade civil.

A autora (LAGAZZI, Op. Cit.), retomando Naves, ressalta que a representação jurídica do Estado, fundada na separação entre o Estado (esfera pública) e a sociedade civil (esfera privada), exclui da esfera pública a representação de classe, entendida como representação de interesses particulares. Dessa forma, "o acesso dos sujeitos à esfera pública estatal só é permitido aos indivíduos despojados de sua condição de classe e qualificados por uma determinação jurídica: o acesso ao Estado só é permitido aos indivíduos na condição de cidadãos" (p.78) ${ }^{8}$.

É por esse mecanismo que o Estado pode estabelecer o meio de expressão jurídico sob a forma de interesse geral, apesar dos diversos e contraditórios interesses particulares que permeiam a sociedade civil, de forma que, ao negar as classes, nega-se também a própria contradição, erguendo aí um lugar de 'não contradição', onde se realiza o ‘bem comum'. E, assim, a cidadania, que possui como pré-construído o sentido do público em oposição ao privado, está sobredeterminada pelo sentido de 'bem comum', naturalizado pelo senso comum, sem que ocorram profundas reflexões sobre para quais direções apontam tais sentidos (Ibid.).

A cidadania, assim, naturaliza o cidadão como um sujeito livre, consciente e lutador, pois ser cidadão passa pelo 'lugar' de participar ativamente para construir algo melhor, pelo direito à conquista, e também pelos deveres. Assim (Ibid., p.82-83):

O cidadão passa a ser alguém em quem depositar as esperanças de um país melhor, de uma sociedade mais promissora. Com isso, a formulação da cidadania torna-se reafirmação constante da individualização nas sociedades de estado e passa a ser um produto democrático. (...) Em sua abrangência imaginariamente irrestrita, o

\footnotetext{
${ }^{8}$ Para a AD, as classes sociais não possuem limites fixos, estanques e definidos pela classificação a priori.
} 
'bem comum' aparece como causa sem falha da democracia liberal, formulação pacificadora da sociedade capitalista. (...) Ficamos todos significados como sujeitos de vontades equivalentes (...) (mas) reafirmados em suas vontades.

Dessa forma, o funcionamento ideológico constitutivo da noção da cidadania reforça o jogo da responsabilização no indivíduo e, portanto, o apagamento das condições de produção e das questões sócio-históricas. Os sujeitos seriam, assim, os responsáveis por construir um mundo melhor, e teriam o controle dessa ação, dessa vontade e essa liberdade, o que apaga as questões do assujeitamento e das filiações ideológicas.

Esses elementos sobre a cidadania como constitutiva do funcionamento jurídico e das relações sociais, distantes, portanto, de um 'bem comum', nos permite refletir em outras direções além dos sentidos das generalizações e abstrações e da necessidade de formar um consenso a partir de políticas públicas, e também pode nos permitir construir algo em uma direção diferente, frente às condições materiais de produção.

Um discurso sustentado pela oposição a algo (com esse algo a ser 'combatido'), pode ser fundamental para delinear uma determinada área de saber, como algumas análises materialistas do Tratado de EA, que se opõe a uma outra EA desenvolvimentista ${ }^{9}$.

No ProNEA também há um discurso de oposição que sustenta o texto, e circula no eixo central de noções de participação, cidadania, coletividade e democracia, que são valores e ideias constantemente reafirmadas em todos os itens que compõem o documento, produzindo essa regularidade temática específica. Isso está em funcionamento pela constante contestação ao autoritarismo, 'lugar' de que o Estado 'falou' em muitos momentos históricos.

A recusa ao autoritarismo, que nos põe em direção à democracia, pode ser entendida como um movimento desejável, porém há muitos problemas que constituem a democracia, que não chegam a ser discutidos e pensados, o que impede um deslocamento para outras direções, para direções mais profícuas das relações sociais e dessas com o Estado.

Ficamos 'reféns' no trabalho da sustentação de discursos de oposição, estando ao mesmo tempo impossibilitados de olhar para a história e para as condições de produção e pré-construídos que sustentam sentidos estabilizados e naturalizados. A

\footnotetext{
${ }^{9}$ Análises materialistas integrantes da tese que deram origem a esse artigo.
} 
demanda de opor-se ao outro absorve o sujeito em estratégias contrárias e, por isso, previsíveis.

Reconhecemos a importância de negar o autoritarismo e reiterar a democracia, mas a armadilha é justamente que, ao focarmos com força esse 'fantasma' ou 'inimigo', nos prendamos nas determinações que o próprio liberalismo já delimita e nos impõe, enquanto a construção de algo novo nos 'foge' de vista.

Assim, reconhecemos o quanto é significativo o ProNEA se alinhar com e se sustentar no Tratado de EA, reiterando seu discurso como uma resposta crítica ao ambientalismo desenvolvimentista. Porém, o que ocorre nesse funcionamento ideológico é que, apesar da oposição, pois ambas as perspectivas se identificam com argumentos distintos, tanto o sujeito-da-ação-coletiva como o sujeito-neoliberal estão tomados pela necessidade de agir um contra o outro, focados cada qual em contraargumentar, envolvidos completamente pelos argumentos contrários do outro. E com isso não conseguem se abrir para o inesperado, para novas direções, para outros sentidos possíveis. Reafirma-se, com essa prática de oposição, o centramento do sujeito, e o olhar para a história fica anuviado. Para apontar para outra perspectiva, queremos abrir as significações da EA em uma direção materialista: uma EA materialista fortalecendo uma EA crítica.

\section{A noção de sujeito-de-direito e a responsabilização do indivíduo}

Para podermos aprofundar esta análise materialista do ProNEA, é fundamental que possamos tratar da questão da cidadania e da noção de sujeito-de-direito.

O modo de produção capitalista funda suas relações jurídicas baseado na noção de sujeito-de-direito, ou seja, o assujeitamento ao Estado Moderno impõe como formasujeito-histórica o sujeito-de-direito, que é aquele que responde por si, sob a afirmação de que “Todos são iguais perante a lei” - Constituição Federal (Lagazzi, 1988).

Pêcheux (2009) chama de efeito ideológico elementar a evidência de que 'eu' e 'você' somos sujeitos. O poder do Estado ganha força no complexo jogo da individuação, no qual 'cada um' e 'todos' reafirmam o funcionamento jurídico. Imaginariamente somos cidadãos de um Estado constituído.

Para ampliarmos essa reflexão sobre o cidadão na relação com o Estado, trazemos Haroche (1992), que nos conta que por volta do século XIII havia um sujeitoreligioso identificado com os textos e dogmas cristãos, com os rituais religiosos, e que essa ordem apoiava-se mais no direito das pessoas e menos nas relações econômicas, o 
que mudou com o enfraquecimento deste poder religioso frente ao poder do Estado, em torno do século X, e teve seu auge no século XVIII com as modificações dos modelos econômicos.

Assim, essa transição inicia-se com a expansão econômica, sendo a questão do sujeito nevrálgica: há uma condução e uma redefinição do sujeito que, progressivamente, é um "sujeito à exação" (sujeito à cobrança), que vem substituir o sujeito religioso - uma sobredeterminação do jurídico sobre o religioso - um sujeito que é religioso e ao mesmo tempo político, que é, mais ou menos, "determinador de seu próprio discurso" (Ibid., p.59).

O século XIII já conhecia o artesanal e urbano, e iniciou uma abertura à ideia de lucro. O comércio se sedentariza e isso tem uma estreita ligação com os progressos da instrução, da escrita, e, logo, do progresso do aparelho jurídico. A partir já do século XI, há as reinvindicações dos direitos e liberdades aos artesãos e comerciantes, e havia os camponeses que lutavam pelo reconhecimento de seus direitos, 'resgatando' sua liberdade. "Todas essas reinvindicações revestem-se de um caráter fundamentalmente jurídico. Conduzem, inevitavelmente, à ideia de um 'sujeito-de-direito', tendo desde então direitos e deveres, um sujeito responsável por seus feitos e gestos” (Ibid., p.68).

A transformação econômica, ideológica e necessariamente jurídica ainda no sistema feudal dá ao sujeito a possibilidade de se tornar livre mediante a possibilidade que lhe dá o senhor de se tornar um sujeito-à-exação - os camponeses se endividavam para comprar sua 'liberdade' (Ibid.).

A constituição de um Estado centralizador, o que também determinou o progresso do jurídico, configura um sujeito que se vê como único, responsável por si mesmo, podendo, entretanto, entrar para o anonimato de ser 'qualquer um'. Essa questão de relativizar uma verdade diminui muito a autoridade religiosa, e há a possibilidade, por exemplo, de um sujeito filósofo ${ }^{10}$ escapar por um trabalho de reflexão do assujeitamento religioso, ou seja, um sujeito então 'livre' pensador (Ibid.).

Sobre o dogma cristão, que descarta uma autonomia do sujeito, Haroche (Op. Cit., p.65) diz:

A crise do século XIII marca o início de um processo irreversível. Muito lentamente (...) desliza-se, não sem obstáculos, da dependência

\footnotetext{
${ }^{10}$ Aqui temos o pensamento de Averróis que formula uma teoria política da religião, porém é somente no século XVI que Spinoza, no Tratado Teológico-político, formula a noção de política que se apoia na religião.
} 
mais total ao dogma para um individualismo que, de imperceptível, triunfa no século XIX com o romantismo.

Desta forma, o sujeito-de-direito foi se tornando uma noção constitutiva do caráter humano, do cidadão, ou seja, é como nos reconhecemos socialmente hoje. Porém, ao mesmo tempo em que nos 'vemos' como cidadãos únicos, o Estado 'fala' com todos ao mesmo tempo, 'na injunção jurídica da responsabilidade'. Direitos e deveres são, então, a antinomia constitutiva de nossa sociedade (LAGAZZI, 2010b). Como sujeitos-de-direitos, então, acreditamos em nossa vontade e liberdade, acreditamos ser fonte dos sentidos por nós ditos. Os processos de individuação e o efeito ideológico elementar são elementos constitutivos das redes de tensões que vivemos e pelas quais nos significamos.

O capitalismo, sendo o modo de produção atual, tem como processo, então, a individuação do sujeito, que não é psicológica, mas política. E tem no Estado um espaço institucionalizado e significado pelo poder como espaço onde os sujeitos se inscrevem, nos trazendo uma outra perspectiva desta territorialidade de cidadãos, em nosso caso, brasileiros. Espaço gerenciado, espaço significado pela relação com o poder (Orlandi, 2010b).

Atualmente a cidade é um "pano de fundo", é uma realidade que se impõe. Grande número de indivíduos diferentes concentrados num mesmo espaço. O início da civilização ocidental ocorre com a fixação permanente dos povos anteriormente nômades na bacia do mediterrâneo e as cidades começam a se expandir, sendo um dos resultados e pressuposto do desenvolvimento capitalista (ORLANDI, 2004, p.12). Pensar os sujeitos na atualidade é levar em consideração a sobredeterminação do urbano, situação que ocorre inclusive para povos que não moram em cidades (ORLANDI, 2001). A cidade é o fato político da contemporaneidade (ORLANDI, 2010b).

Para Orlandi (2010a), as políticas urbanas atuais consideradas democráticas estão fundamentadas na busca do consenso e da participação social nas diferentes instâncias institucionais da cidade, ou seja, são fundamentadas numa lógica consensual que é considerada ideal para solucionar conflitos sociais pressupondo a existência de um lugar comum para as aspirações e necessidades dos grupos sociais. O consenso traz, então, a noção de unidade, de uma ligação que une a humanidade. 
A reflexão aqui trazida nos permite compreender a questão do assujeitamento pela forma histórica de existência em nossa atualidade e, desta forma, faz com que seja possível, a partir disso, avançarmos em outra direção.

\section{ProNEA na relação com os cidadãos}

Para dar mais elementos a uma reflexão sobre a política da educação ambiental, trazemos Pfeiffer (2010) com algumas análises discursivas de políticas de educação propostas pelo MEC.

Em tais análises, Pfeiffer (2010, p.86) encontra um funcionamento que é dito como comum a todas as políticas públicas na história brasileira: "as políticas sociais são importantes no sentido de amenizar as desigualdades originadas pelo mercado", como uma "ação humanitária que busca ajudar aos desfavorecidos".

Pfeiffer (2010, p.90), citando os estudos de Lopes (2006) ${ }^{11}$, compreende que a política de currículo é como um "pacote lançado de cima para baixo", cabendo às escolas implementá-lo ou resistir a ele. Estão presentes efeitos de responsabilização e competição numa cultura da performatividade. Ocorre a responsabilização do indivíduo pelo seu sucesso ou fracasso (individualização da culpabilidade), e restringe-se a educação a uma relação com o mercado.

A autora destaca, ainda, que a cultura da performatividade pressupõe que exista um conjunto de performances que são adequadas e que também existiria um currículo capaz de ensinar, reforçando a percepção de uma 'cultura comum' voltada ao mercado ou ao contexto social mais amplo. Assim, nos diz a autora: “(...) nesse imbricamento, vemos funcionar o pragmatismo tomado pelo contorno da universalização respaldada na reivindicação da diferença" (Ibid., p.91).

Pensando especificamente o ProNEA a partir das reflexões de Pfeiffer, consideramos importante marcar que a questão da consulta pública, a questão de ser um documento aberto para permanentes revisões, e também o fato de ter o Tratado de EA como guiança em seus escritos (tendo em vista as condições de produção da fundação do Tratado de EA) permitem-nos dizer que este documento não se alinha à cultura de performatividade e nem se coloca como pacote lançado de cima para baixo. Mas um ponto nos aflige e diz respeito a amenizar as "desigualdades provocadas pelo mercado" (Pfeiffer, 2010, p.86), marcada nas formulações "sociedades em segmentos sociais

${ }^{11}$ LOPES, Alice. Discurso nas políticas de currículo. Currículo sem fronteiras, v.6, n.2, 2006. 
excluídos" (Brasil, 2005, p.17) ou "sociedades em condições de vulnerabilidade" (Ibid., p.18).

Também o recorte a seguir reitera a busca por amenizar as desigualdades:

Com a proposta de mudança social entendemos como necessárias a superação da injustiça social, da apropriação da natureza e da humanidade pelo Capital, da desigualdade social e dos processos em que se privatizam lucros e socializam as mazelas decorrentes entre as parcelas desfavorecidas da população (Ibid., p.18-19).

No entanto, uma ressalva é importante no recorte acima, e diz respeito à desnaturalização da noção de 'individualização da culpabilidade'. Há algo que escapa e para o que queremos chamar a atenção, um equívoco que, a nosso ver, constitui o objetivo de "superação", afirmado no recorte acima.

Atribuir a cidadãos participativos essa responsabilidade, que como vimos são sujeitos identificados na dicotomia entre sociedade civil e Estado, identificados nas relações que fundam a individualização, ainda que não apenas como culpabilidade (pois o ProNEA desnaturaliza esse ponto), é endossar a individualização que se afirma também pela conscientização, pela possibilidade (e necessidade!) de ação dos sujeitos. Portanto, temos aqui uma questão que faz patinar e precisa ser discutida.

A revolução burguesa se sustenta pela noção de igualdade entre os pobres e ricos, a noção de liberdade, que reforça a noção de 'individualização da culpabilidade' dos sujeitos-de-direito. Nestes termos, como já afirmamos acima, o documento ProNEA trabalha na direção de não endossar a 'individualização da culpabilidade', mas reforça a noção de liberdade, constitutiva de todos nós, sujeitos-de-direito, por exemplo quando reivindica a superação, o empoderamento, estratégias, ações, participação. Mesmo que reiteremos o coletivo, não podemos alinhá-lo à liberdade individual e à democracia nos moldes capitalistas.

Neste momento, interessa-nos perguntar em que medida o ProNEA afeta as fronteiras do dentro e do fora do aparelho Estado e suas relações com o político e, ainda, em que medida abre a possibilidade de um deslocamento e/ou uma atualização do papel do Estado?

Lagazzi (1987), em seus estudos sobre relações de poder e senso comum no cotidiano (juridismo) afirma que a possibilidade do ser e do dizer vem de uma insatisfação, de uma resistência, de uma falta que é uma não-saturação, que é o que pode conduzir a um deslocamento, não como desassujeitamento, o que é impensável, 
mas a uma mudança, a um outro possível. Isto pode se dar enquanto outras relações de identificação para o sujeito, outros modos de reconhecimento.

Essa autora (Ibid., idem), cita Haroche (1984): “O Estado define-se pela literalidade, por suas leis explícitas. (...) Dessa forma, a relação do sujeito ao Estado só pode ser pensada sob a forma de subordinação, opressão, disciplinarização da subjetividade".

Nestes termos, podemos refletir sobre a política pública de EA, mais propriamente o ProNEA aqui analisado, como uma briga nessa relação do Estado com os seus cidadãos, num deslocamento do papel deste Estado. Há deslocamento na construção de sua política que busca não homogeneizar as noções de meio ambiente e educação, mas historicizá-las.

O ProNEA busca significar na direção de cidadãos como sujeitos políticos em coletividades enraizadas no tempo e no espaço, em uma Formação Discursiva que deslocaria os sentidos de coerção e autoridade do aparelho ideológico Estado, estabelecendo uma noção de parceria, filiando-se a uma Formação Discursiva circunscrita pelo sentido de movimento social, apontando para um efeito de sentido de parceria política entre sujeitos políticos.

\section{Concluindo a análise e abrindo a novas questões}

Afirmamos que em uma análise não podem caber todas as análises. Fica aqui um recorte possível de uma análise materialista da 3a. versão do Programa Nacional de EA.

Com a análise do texto do ProNEA ressaltamos o foco desse documento na afirmação da participação política em processos coletivos na direção da democracia. Esse discurso aponta para um fortalecimento do Estado enquanto mobilizador de ação política, significando por esta ruptura com o discurso tradicional político. Consideramos importante nos perguntarmos: Qual(is) seria(m) a(s) possível(is) paráfrase(s) para democracia neste discurso? O que sustenta este termo no ProNEA?

Podemos dizer, após a análise, que esse discurso do ProNEA se afasta de sentidos filiados a uma formação discursiva autoritária e coercitiva, e se marca por sentidos filiados a uma outra formação discursiva constituída por uma memória de movimentos sociais, apresentando como pré-construído a força da ação política do povo (educação como ação política), povo que se reconhecendo como sujeito político, poderia e iria estabelecer uma democracia efetiva e mudar as relações impostas pelo modo de produção atual, o capitalismo. Esse povo estaria empoderado e livre de 
qualquer ideologia, o que é impensável na perspectiva discursiva.

Essa noção de educação como ação política é oriunda de uma linha marxista que faz referência à frase de Marx "O homem faz a história...", mas num determinado recorte marxista considerado, sob a perspectiva materialista, como idealista, pois não se ancora na noção de descentramento do sujeito. Ou seja, sob a perspectiva materialista, os homens fazem a história que é possível ser feita - história sem sujeito nem fim.

Terminamos, aqui, ressaltando que nossas análises nos permitiram observar que o ProNEA investe na busca de novas direções de significação, de deslocamentos importantes para mudanças sociais. Ao mesmo tempo, nossas análises também trouxeram noções que a $\mathrm{AD}$ permite mobilizar e que apontamos como contribuições para a ampliação da política, num modo de realizar uma crítica aos pontos de equívoco que sustentam as noções de liberdade e democracia. Vale ressaltar que a ideia de Estado ausente que reforça políticas neoliberais em nenhum momento dessa pesquisa foi visto, identificado ou entendido.

Afirmamos, assim, a importância em discutirmos a noção de sujeito-de-direito que é sustentada pelo documento, que fortalece a ideia de autonomia e liberdade dos cidadãos, e confrontá-la com discussões coletivas de reapropriação do documento e consequentes modificações deste. Acreditamos que isso possa contribuir para abrir processos de significação em outras direções bastante produtivas. Consideramos de fundamental importância que noções como as de "democracia", "sujeito político" e "educação ambiental" continuem como noções abertas, sobre as quais é sempre importante perguntar.

\section{Referências bibliográficas}

ALTHUSSER, Louis. Materialismo histórico e materialismo dialético. Trad. Elisabete A. Pereira dos Santos. 2ed. São Paulo: Global, 1986.

ALTHUSSER, Louis. Observação sobre uma categoria: "PROCESSO SEM SUJEITO NEM FIM(S)”. In: ALTHUSSER, L. Posições I. Rio de Janeiro: Graal, 1978.

ALTHUSSER, Louis. Ideologia e aparelhos ideológico do Estado. Trad. Joaquim José de Moura Ramos. Porto: Editorial Presença, 1974.

BRASIL. ProNEA/Educação Ambiental por um Brasil Sustentável - ProNEA, Marcos Legais e Normativos. - 4ed - Brasília: Ministério do Meio Ambiente/Ministério da Educação. 2014. Disponível em: <http://www.mma.gov.br/publicacoes/educacaoambiental/category/98-pronea>. Acesso em 21 mar 2015.

BRASIL. Portfólio do Órgão Gestor da Política Nacional de Educação Ambiental. Brasília: Série Documentos Técnicos, número 7, Brasília, DF, 2006a. 
BRASIL. ProFEA - Programa de formação de educadores(as) ambientais: Por um Brasil educado e educando ambientalmente para a sustentabilidade. Brasília: Ministério do Meio Ambiente/ Diretoria de Educação Ambiental. 2006b.

BRASIL. ProNEA - Programa Nacional de Educação Ambiental. Ministério do Meio Ambiente, Departamento de Educação Ambiental; Ministério da Educação, Coordenação Geral de Educação Ambiental. - 3 ed - Brasília: MMA, DF, 2005. Disponível

em: $\langle$ http://portal.mec.gov.br/secad/arquivos/pdf/educacaoambiental/pronea3.pdf $>$. Acesso em 21 mar 2015.

BRASIL. Decreto No 4.281/02 - Regulamentação da Política Nacional de Educação Ambiental. Presidência da República, Brasília, 2002.

Lei no 9.795/99 - Política Nacional de Educação Ambiental. Presidência da República, Brasília, 1999.

HAROCHE, Claudine. Fazer Dizer, Querer Dizer. Trad. Eni Pulcinelli Orlandi. São Paulo: Hucitec, 1992.

HAROCHE, Claudine. Faire Dire, Vouloir Dire. Paris: PUL, 1984. Apud: LAGAZZI, S.M. O juridismo marcando as palavras: uma análise do discurso cotidiano. Dissertação de mestrado, Instituto de Estudos da Linguagem, UNICAMP. 1987.

LAGAZZI, Suzy M. The social in scene in significant materiality. Acta Scientiarum language and culture, v32, n2, 153-161p. 2010a.

LAGAZZI, Suzy M. O confronto político urbano administrado na instância jurídica. In: ORLANDI, E.P. (org.). Discurso e políticas públicas urbanas - a fabricação do consenso. Campinas: RG, 2010 b.

LAGAZZI, Suzy M. O desafio de dizer não. Campinas: Pontes, 1988.

LAGAZZI, Suzy M. O juridismo marcando as palavras: uma análise do discurso cotidiano. Dissertação de mestrado, Instituto de Estudos da Linguagem, UNICAMP. 1987.

NAVES, Márcio B. Marxismo e direito - um estudo sobre Pachukanis. São Paulo: Boitempo, 2008.

ORLANDI, Eni, P. (org.) Discurso e políticas públicas urbanas - a fabricação do consenso. Campinas: RG, 2010a.

NAVES, Márcio B. Os sentidos de uma estátua: espaço, individuação, acontecimento e memória. Entremeios: revista de estudos do discurso. v.1, n.1, jul, 2010 b.

NAVES, Márcio B. Discurso e Texto: formulação e circulação dos sentidos. 3ed. Campinas: Pontes, 2008.

NAVES, Márcio B. Interpretação - autoria, leitura e efeitos do trabalho simbólico. 5ed. Campinas: Pontes, 2007.

NAVES, Márcio B. Cidade dos Sentidos. Campinas: Pontes, 2004.

NAVES, Márcio B. Cidade Atravessada: os sentidos públicos no espaço urbano. Campinas: Pontes, 2001.

NAVES, Márcio B. Análise de discurso - princípios e procedimentos. Campinas: Pontes, 1999. 
PÊCHEUX, Michel. Semântica e Discurso: uma crítica à afirmação do óbvio. Trad. Eni P. Orlandi et al. 4ed. Campinas: Unicamp, 2009.

PFEIFFER, Cláudia R. Castellanos. Políticas Públicas de Ensino. In: ORLANDI, E. P. (org.). Discurso e políticas públicas urbanas - a fabricação do consenso. Campinas: RG, 2010.

RODRÍGUEZ-ALCALÁ, Carolina. Em torno das observações para uma Teoria Geral das Ideologias de Thomas Herbert. Estudos da Língua(gem), Vitória da Conquista, n.1, p.15-21, 2005.

SILVA, Telma D. O cidadão e a coletividade: as identificações produzidas no discurso da educação ambiental. In: Trajber, R. \& Manzochi, L.H. (orgs.). Avaliando a educação ambiental no Brasil: materiais impressos. São Paulo: Gaia, 1996.

SORRENTINO, Marcos et all. Política pública nacional de educação ambiental nãoformal no Brasil: gestão institucional, processos formativos e cooperação internacional. In: CONFERÊNCIA INTERNACIONAL DE EDUCAÇÃO AMBIENTAL, 4., Ahmedabad, Índia, 2007. Anais... Ahmedabad: 24-28 nov. 2007.

SORRENTINO, Marcos. Educação Ambiental como Política Pública. Educação e Pesquisa, São Paulo,v.31, n.2, p.285-299. 2005. 


\section{Para citar essa obra:}

LUCA, A. Q. LACAZZI, S. M. SORRETINO, M. Um olhar político para a educação ambiental do Programa Nacional De Educação Ambiental (ProNEA). In: RUA [online]. $n^{\circ}$. 22. Volume 1, p. 151-174 - ISSN 1413-2109 - Junho/2016. Consultada no Portal Labeurb - Revista do Laboratório de Estudos Urbanos do Núcleo de Desenvolvimento da Criatividade.

http://www.labeurb.unicamp.br/rua/

Capa: Disponível em: http://www.mma.gov.br/publicacoes/educacao-ambiental/categ ory/98-pronea

\section{Laboratório de Estudos Urbanos - LABEURB}

Núcleo de Desenvolvimento da Criatividade - NUDECRI

Universidade Estadual de Campinas - UNICAMP

http://www.labeurb.unicamp.br/

\section{Endereço:}

LABEURB - LABORATÓRIO DE ESTUDOS URBANOS

UNICAMP/COCEN / NUDECRI

CAIXA POSTAL 6166

Campinas/SP - Brasil

CEP 13083-892

Fone/ Fax: (19) 3521-7900

Contato: http://www.labeurb.unicamp.br/contato 